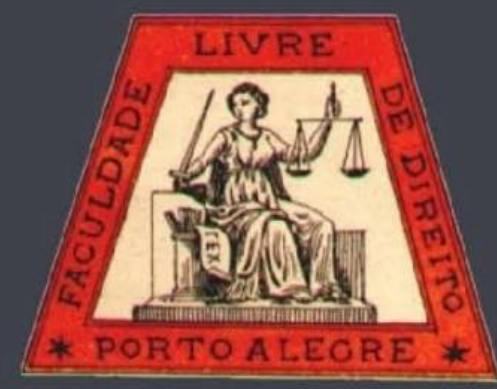

\title{
O direito social ao trabalho como condição à busca pela felicidade
}

The social right to work as a condition to persuade happiness

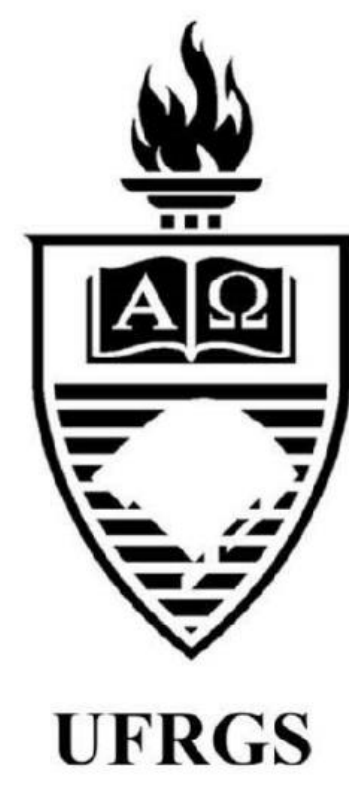

Camila Martinelli Sabongi

Universidade Estadual Paulista

Victor Hugo de Almeida

Universidade Estadual Paulista

Igor Assagra Rodrigues Barbosa

Universidade de São Paulo 


\title{
O direito social ao trabalho como condição à busca pela felicidade
}

\author{
The social right to work as a condition to persuade happiness
}

Victor Hugo de Almeida*

\author{
Camila Martinelli Sabongi**
}

Igor Assagra Rodrigues Barbosa***

\section{REFERÊNCIA}

ALMEIDA, Victor Hugo de; SABONGI, Camila Martinelli; BARBOSA, Igor Assagra Rodrigues. O direito social ao trabalho como condição à busca pela felicidade. Revista da Faculdade de Direito da UFRGS, Porto Alegre, n. 38, p. 220-233, ago. 2018.

\section{RESUMO}

Conquanto não haja previsão explícita no ordenamento pátrio, o direito à felicidade tem sido estampado em diversas decisões judiciais como desdobramento do princípio da dignidade da pessoa humana, relacionando-se, ainda, com a concretização dos direitos sociais e dos valores sociais do trabalho, fundamentos previstos constitucionalmente. Elencado como direito mínimo e indispensável à garantia de uma existência digna, tendo como escopo a preservação, o direito ao trabalho livre e emancipador é constitucionalmente previsto, de importância reconhecida para o pleno desenvolvimento do indivíduo, tanto para suprir suas necessidades essenciais, possibilitando sua existência digna, mas também como forma de se realizar pessoal e socialmente. Este artigo visa analisar os contornos do direito ao trabalho, sua relação com o direito à busca pela felicidade e a concretude desses na realidade do indivíduo no mundo contemporâneo do trabalho. Trata-se de uma pesquisa de natureza teóricoexploratória, pautada no método de levantamento de dados por meio da técnica de pesquisa bibliográfica, e, como método de abordagem, o indutivo. A análise proposta evidencia a necessidade de se implementar políticas públicas de conscientização que prezem pela efetivação dos direitos humanos, sociais e trabalhistas, de forma a promover o direito ao trabalho digno, realizador e emancipador, que corrobore com o bem-estar do trabalhador, possibilitando, assim, a felicidade em sua plenitude, tanto coletiva como subjetiva.

\section{ABSTRACT}

Although there is no explicit provision in the country's legal system, the right to happiness has been printed in several judicial decisions as a result of the principle of the dignity of the human person, and is related to the realization of social rights and social values of work, fundamentals provided for in the Constitution. Classified as a minimum and indispensable right to guarantee a dignified existence, having as its objective the preservation, the right to free and emancipatory work is constitutionally foreseen, of recognized importance for the full development of the individual, both to meet their essential needs, enabling their existence dignified, but also as a way of achieving oneself personally and socially. This work aims to analyze the right to work contours, its relation to the right to pursuit happiness and the concreteness of both rights in person's reality in the contemporary world of work. This is a theoretical and exploratory research guided by a data collection method through literature research technique, and as an approach method, it will be used the inductive method. The proposed analysis evidences the need to implement public awareness-raising policies that promote the realization of human, social and labor rights, in order to promote the right to decent, fulfilling and emancipatory work that corroborates the worker's well-being, thus making happiness possible in its fullness, both collective and subjective.

\footnotetext{
* Professor de Direito do Trabalho da Universidade Estadual Paulista “Júlio de Mesquita Filho" (UNESP), São Paulo. Doutor em Direito pela Faculdade de Direito da Universidade de São Paulo (USP).

** Mestranda do Programa de Pós-Graduação em Direito da Universidade Estadual Paulista "Júlio de Mesquita Filho" (UNESP), São Paulo. Bolsista Fapesp 2016-2018.

*** Mestrando do Programa de Pós-Graduação em Direito da Universidade de São Paulo (USP).
} 
PALAVRAS-CHAVE

Direito Social ao Trabalho. Felicidade. Direitos Humanos.
KEYWORDS

Social Right to Work. Happiness. Human Right.

\section{SUMÁRIO}

Introdução. 1. A efetivação do direito ao trabalho. 2. O direito à busca pela felicidade. 3. $\mathrm{O}$ direito ao trabalho como meio de concretização do direito à busca pela felicidade. Conclusão. Referências.

\section{INTRODUÇÃO}

A Declaração dos Direitos Humanos da Organização das Nações Unidas (ONU) de 1948 já abordava os direitos sociais, incluindo o direito ao trabalho. No Brasil, a concepção universalista dos direitos sociais foi incorporada pela Constituição de 1988, cuja Norma dedicou o Capítulo II (Dos direitos sociais) à previsão desses direitos (MACHADO, 2014).

$\mathrm{O}$ ordenamento jurídico brasileiro preza pela valorização do trabalho, tendo em vista a opção do constituinte, já no art. $1^{\circ}$ da Constituição Federal de 1988 (CF), pela adoção dos valores sociais do trabalho (Inciso IV) como um dos fundamentos da República Federativa do Brasil. Em adição, em seu art. $6^{\circ}$, a Constituição ainda traz a previsão do trabalho como direito social. Dessa forma, o direito ao trabalho é elencado como direito mínimo e indispensável à garantia de uma existência digna, tendo como escopo a preservação, por parte do Estado, de certas situações incorporadas ao patrimônio humano (MACHADO, 2014). Estes patrimônios humanos a serem defendidos não se restringem a fatores materiais, mas também englobam os imateriais (art. $5^{\circ}, \mathrm{V}, \mathrm{CF}$ ).

Corroborando com os artigos supracitados, encontra-se ainda a previsão da redução das desigualdades sociais e o pleno emprego no art. 170, VII e VIII, da CF, com o fim de possibilitar a todos uma existência digna por meio do trabalho, conforme os ditames da justiça social, a qual, em conjunto com o bem-estar social, é o objetivo da ordem social, que tem como base o primado do trabalho - art. 193, CF (MACHADO, 2014).

Todavia, o trabalho não é apenas um meio de se buscar a existência digna. A atividade profissional oferece particular satisfação quando é livremente eleita, permitindo que o indivíduo utilize suas inclinações preexistentes e tendências instintivas evoluídas, sendo fator relevante como caminho à felicidade (FREUD, 2002).

O direito ao trabalho livre e emancipador é constitucionalmente previsto, de importância reconhecida para o pleno desenvolvimento do indivíduo, tanto para suprir suas necessidades essenciais, possibilitando sua existência digna, mas também como forma de se realizar pessoal e socialmente (SABONGI, 2015) em seu trabalho.

No entanto, a maioria dos seres humanos só trabalha em face da necessidade, sendo esta a causa de diversos problemas sociais (FREUD, 2002). Contemporaneamente, mesmo contando com um grande número de pessoas empregadas em nível global (aproximadamente 3 bilhões de habitantes), cerca de 43,5\% desses indivíduos vivem abaixo da linha de pobreza de 2 dólares diários (OIT, 2014).

No Brasil, segundo o Instituto Brasileiro de Geografia e Estatística (IBGE), no terceiro trimestre de 2015, cerca de 92,1 milhões de brasileiros estavam empregados no país (UOL, 2015), sendo que, segundo dados da Receita Federal do Brasil, o número de trabalhadores com renda superior a 160 salários mínimos no mesmo ano foi de 71.440 , ao passo que 20.738.173 tem renda inferior a 10 salários mínimos com maior concentração de população com renda entre 5 e 3 
salários mínimos (ALVARENGA, 2015). Em adição, deve-se observar que esses números são referentes aos trabalhadores que declaram Imposto de Renda (IR), ou seja, esses dados ignoram o trabalho informal, que absorve grande parcela da mão de obra brasileira. Nesse cenário, resta evidente a grande concentração de renda que assola o país, havendo uma clara discrepância entre os salários dos brasileiros, sendo a grande maioria relegada a uma situação de necessidade material.

Segundo Leonardo Wandelli (2008, p. 5), “é evidente que, diante desses números, a disputa no mercado pela sobrevivência por meio do trabalho habita o reino da miséria, da opressão, onde a discriminação é a medida do lugar no mundo de cada um, que já na infância se revela implacável".

Assim, pode-se observar que há um diapasão entre o discurso constitucional e a prática dos direitos humanos, dentre eles os sociais, e o direito ao trabalho não foge a tal impasse. Nesse sentido, David Sanchez Rubio (2015) aborda a consolidação do abismo que existe entre a teoria e a prática dos direitos humanos, que acaba por provocar uma cultura jurídica social passiva e anestesiada.

A universalidade dos direitos humanos se constrói sobre discursos que defendem inclusões em abstrato de todas as pessoas, mas sobre a base trágica de exclusões concretas, individuais e coletivas, marcadas pela nacionalidade, o racismo, o endocentrismo, o classismo, a riqueza como fim em si mesmo (RUBIO, 2015). Dessa forma, como preceitua Alexandre Mendes (2011), deve-se buscar afastar o Direito de suas condições transcendentais, abstratas e ideais que o separam das condições de sua realização.

Nesse contexto, o presente estudo visa analisar os contornos do direito ao trabalho e a concretude desse direito na realidade do indivíduo, considerando o contexto em que se encontra, ou seja, o mundo contemporâneo do trabalho. Adicionalmente, pretende-se analisar o papel que o direito ao trabalho possui na concretização do direito à busca da felicidade, de modo a averiguar até que ponto o trabalho é considerado e concretizado como um meio de emancipação e liberdade, ou seja, meio de alcance de uma existência digna condizente com a busca pela felicidade.

Trata-se de uma pesquisa de natureza teórico-exploratória. Diante disso, utilizar-se-á do método de levantamento de dados por meio da técnica de pesquisa bibliográfica em materiais já publicados (por exemplo, doutrinas, artigos científicos, sítios eletrônicos, legislação, jurisprudência, monografias, entre outros) e, como método de abordagem, o indutivo.

\section{A EFETIVAÇÃO DO DIREITO AO TRABALHO}

Enfrenta-se a redução do direito ao trabalho, direito humano a ser zelado, previsto constitucionalmente como direito social no art. $6^{\circ}$ e comumente interpretado como apenas uma garantia à subsistência.

$\mathrm{O}$ direito ao trabalho é interpretado e consequentemente aplicado pelo Estado como um direito do cidadão de buscar suprir suas necessidades básicas materiais por meio do trabalho. Todavia, esse entendimento é simplista e ignora que o trabalho digno e emancipador traz a possibilidade de realização ao indivíduo, que tem a chance de ver em suas tarefas laborais diárias, desde que realizadas em um meio ambiente do trabalho equilibrado, um meio de alcançar bem-estar pessoal, socialização e felicidade.

Faz-se necessário promover uma reconstrução da compreensão da relação do trabalho com a subjetividade humana, com o intuito de recuperar a legitimidade da reivindicação pelo direito ao trabalho (WANDELLY, 2008). 
Para Leonardo Wandelly (2008), o direito ao trabalho sofre grandes impactos em sua concretude diante da dependência que se tem hoje de enfrentar o próprio esvaziamento do sentido do trabalho. Segundo o autor:

A modernidade capitalista reduziu o trabalho humano a uma específica forma de trabalhar, que subsume o trabalho como produtor de valor para o capital, mas que não resulta em valor de uso para o sujeito que trabalha. Promoveu uma separação radical entre trabalho e vida, ao tempo que excluiu progressivamente os outros modos de relacionar trabalho e vida. Ato contínuo, esse específico modo de trabalhar, que nega o trabalho como direito, no extremo, um trabalho "não-vida", torna-se uma presença avassaladora para a vida das pessoas. Quem não tem um "trabalho" continua tendo o trabalho, que não está, como o referencial de identificação e reconhecimento social e a única via possível de alcançar bens, a começar pelos de sobrevivência. Quem tem um "trabalho", se exaure cada vez mais, ante o medo do risco de desestabilização que pode produzir a sua perda, numa precariedade que raramente viabiliza a construção de um projeto de vida digna (WANDELLY, 2008, p. 6).

Nessa direção, elucida Paulo César do Amaral de Pauli que salários miseráveis, precarização do trabalho, jornadas extensas, descansos suprimidos ou reduzidos são males que afetam milhares de trabalhadores brasileiros, justificando uma redefinição urgente do papel dos direitos humanos nas relações de trabalho. Caso contrário, os trabalhadores serão convertidos em uma massa ajustável às exigências da indústria, do comércio e das empresas a serviço dos interesses do capital. Assim sendo, "os meios necessários à manutenção do sistema econômico brasileiro, que visa ao consumo e à produção como fatores essenciais de sobrevivência, nem sempre se adequam às normas de proteção ao trabalho" (PAULI, 2015, p. 201).

A título de exemplo, pode-se observar a caracterização do dano existencial, ou seja, a frustração do projeto de vida ou da vida de relações do trabalhador, em casos de desrespeito às normas labor-ambientais, como é o caso das violações à duração da jornada de trabalho e do desrespeito às normas de saúde e segurança do trabalho (SABONGI, 2015). Nesse sentido, atenta-se contra a saúde do trabalhador, não apenas física, mas também psíquica, ao se priorizar os lucros em detrimento do bem-estar dos trabalhadores.

Conquanto o aspecto positivo desse cenário seja a possibilidade de que boas práticas corporativas e intervenções efetivas na estrutura organizacional do meio ambiente do trabalho afastem a precarização do trabalho e a violação constante dos direitos humanos na seara juslaboral, o aspecto negativo consiste na dificuldade de se modificar a cultura patronal no país, de modo a conscientizar empregadores que a manutenção do equilíbrio laboral contribui para a satisfação dos trabalhadores.

A questão esbarra na cultura dominante que permeia os direitos humanos e que relega a responsabilidade de efetivação destes apenas ao Estado, não entendendo a sociedade como parte efetiva e atuante na concretização daqueles. Nesse sentido, Boaventura de Sousa Santos (1989) afirma que a concepção moderna dos direitos humanos apresenta limites inegáveis, sendo a primeira justificativa o confinamento destes ao Direito Estatal, limitando seu impacto democratizador.

A postura passiva de depositar a efetivação dos direitos humanos ao Estado, combinada com a ênfase técnico-formal, com a consequente negligencia e negação da real efetividade desses direitos, gera uma distância entre o Direito e o cidadão (WOLKMER, 2006), a qual apenas se amplia com o tempo e aumenta a sensação de impotência e insegurança jurídica.

Essa problemática se faz evidente no âmbito do Direito do Trabalho quando se verifica que diversas normas de proteção ao trabalhador albergadas pelo ordenamento jurídico brasileiro não são concretizadas. A não concretização desses direitos acaba por causar impactos negativos ao trabalhador, uma vez que, assim 
como as condições psicológicas do trabalhador influem no seu trabalho, este também influi naquelas (ALMEIDA; SOUZA, 2013).

\section{O DIREITO À BUSCA PELA} FELICIDADE

A discussão sobre o direito à felicidade traz grandes conflitos, tendo em vista que vários pensadores já se debruçaram sobre a questão. Para Hobbes (2015), a felicidade é o sucesso contínuo do homem em buscar o que deseja, ou seja, o prosperar constante. Não passando de momentos, a felicidade não poderia ser considerada um fim último, sendo mera utopia. Kant (2004) já afirmava que a felicidade é formalmente indeterminável, uma vez que o homem não conseguiria delimitar as condições necessárias para sua felicidade perfeita. No mesmo sentido, para o sociólogo Ruut Veenhoven (1991), a felicidade de um indivíduo é a satisfação que ele possui em sua vida, tendo a felicidade um conceito relativo.

Mesmo havendo certo consenso sobre a indeterminação e relatividade do termo "felicidade", alguns países se preocuparam com a efetivação dessa qualidade na vida de seus cidadãos e utilizaram-se do Direito como ferramenta para tentar efetivar esse estado de espírito em seus territórios ou, pelo menos, o direito de buscar este estado de espírito.

Várias Constituições estrangeiras trazem a felicidade em seus artigos, como a do Japão, da Coréia do Sul, dos EUA, dentre outras. É interessante observar que na Declaração de Direitos da Virgínia, EUA, de 1776, já havia menção ao direito a busca pela felicidade, que foi incluído na Declaração de Independência como direito inalienável do cidadão. Observa-se que o termo "busca da felicidade", utilizado no texto legal norte-americano, demonstra que o objetivo da norma não é assegurar que o cidadão americano seja feliz, e sim que ele tenha a possibilidade, a garantia de buscar a sua felicidade, respeitando-se o aspecto subjetivo deste direito (HORBACH, 2013).

Já na França, na Declaração de Direitos do Homem e do Cidadão (1789), há a primeira noção coletiva de felicidade, preocupando-se com a promoção da felicidade geral. No preâmbulo da Carta Francesa de 1958, ainda vigente, encontrase inclusa a felicidade geral como direito humano consagrado (G1, 2010).

Ao se falar em promoção da felicidade geral, verifica-se a construção de uma noção de felicidade coletiva que leva em consideração a atuação do Estado para a concretização desse contentamento, de forma a se pensar em uma obrigação de atuação no sentido de efetivação da felicidade e não apenas a garantia de uma discricionariedade do cidadão em buscar sua própria felicidade da maneira que escolher. Em outras palavras, enquanto o Direito a buscar a felicidade, como aspecto subjetivo, exige do Estado respeito à liberdade do indivíduo para exercer o que entender como satisfatório para sua felicidade individual, a concretização da felicidade coletiva demanda do Estado ações que tenham como escopo consubstanciar a felicidade.

Segundo Martha Nussbaum (2008), a Psicologia vem se debruçando sobre o estudo desse estado de ânimo, satisfação e prazer que é chamado de felicidade, analisando a hipótese de que esse estado subjetivo teria implicações na formulação e implementação de políticas públicas. Observa-se, assim, a preocupação do meio científico, não apenas jurídico, em entender esse aspecto da felicidade que se relaciona com o bem-estar geral, ou seja, a noção coletiva de felicidade.

Em nível internacional, em assembleia geral, as Nações Unidas aprovaram, em julho de 2011, a resolução $n^{\circ}$ 65/309 que reconhece a busca pela felicidade como "um objetivo humano fundamental" e convida os estados-membros a promover políticas públicas que incluam a 
importância da felicidade e do bem-estar em sua aposta pelo desenvolvimento. Na mesma oportunidade, a assembleia geral convidou os 193 países-membros da ONU a promover medidas que melhor reflitam a importância da busca pela felicidade em suas políticas públicas. Nesse sentido, observa-se o reconhecimento da busca pela felicidade e da necessidade de se prezar pela efetivação desta pela comunidade internacional (UOL, 2011).

O secretario Internacional da ONU, Ban Kimoon, lembrou, em discurso, que "a felicidade não é uma futilidade nem um luxo. É um anseio profundo compartilhado por todos os membros da família humana. Não deve ser negada a ninguém e deve estar acessível a todos" (ONUBR, s.d., online). Em adição, o secretário geral afirmou que apesar da definição de felicidade poder esbarrar em fatores subjetivos e ter significados distintos para pessoas diferentes, há um consenso que buscar a felicidade significa trabalhar para acabar com os conflitos, a pobreza e com outras condições lamentáveis em que muitos seres humanos vivem (ONUBR, s.d.). Completou dizendo:

\begin{abstract}
Essa aspiração está implícita na promessa da Carta das Nações Unidas para promover a paz, a justiça, os direitos humanos, o progresso social e melhores padrões de vida. Agora é a hora de converter essa promessa em ações internacionais e nacionais concretas para erradicar a pobreza, promover a inclusão social e a harmonia intercultural, garantir meios de subsistência decentes, proteger o meio ambiente e construir instituições para uma boa governança. Estas são as bases para a felicidade e o bem-estar humanos (ONUBR, s.d., online).
\end{abstract}

No mesmo sentido, o atual presidente da Assembleia Geral da ONU, John Ashe, clamou à comunidade internacional que prezasse pela manutenção dos três pilares do desenvolvimento sustentável, quais sejam o social, o econômico e o ambiental, acrescentando que "a felicidade é um objetivo humano fundamental, e melhorar políticas públicas em países que podem contribuir para este objetivo é essencial para promover sociedades equitativas para todos" (ONUBR, $\overline{\text { s.d. }}$ online).

No Brasil, o assunto teve destaque com a Proposta de Ementa Constitucional n ${ }^{\circ} 19$ de 2010, que foi apelidada de "PEC da Felicidade", e tinha como finalidade alterar o art. $6^{\circ}$ da Constituição Federal para incluir o direito à busca da felicidade por cada indivíduo e pela sociedade, mediante a dotação pelo Estado e pela própria sociedade das adequadas condições de exercício desse direito (BRASIL, 2015). Todavia, o projeto não prosperou, sendo arquivado em 26/12/2014, nos termos do art. 105 do Regimento Interno da Câmara dos Deputados (fim de legislatura).

A referida proposta visava determinar que os direitos sociais previstos no art. $6^{\circ}$ fossem tidos como essenciais à busca da felicidade. Nesse sentido, buscar-se-ia alcançar o aspecto coletivo da felicidade, ou seja, dar aos indivíduos o essencial para uma vida digna, como educação, saúde, trabalho, moradia, lazer, segurança, previdência social, dentre outros direitos (HORBACH, 2013). É evidente que não se fala aqui da busca da felicidade subjetiva, inerente a cada indivíduo e definida pela percepção deste (RUBIN, 2010).

$\mathrm{Na}$ análise do autor do Projeto da Emenda, Senador Cristovam Buarque, ao se falar em busca da felicidade por meio da educação, da saúde, da moradia, do lazer, da segurança, do trabalho, da previdência social, da proteção à maternidade e à infância, da assistência aos desamparados, entende-se que esses direitos, quando concretizados, têm a possibilidade de promover mais qualidade de vida e a conscientização ao cidadão de que eles não só lhe pertencem, mas também a própria materialização destes e da felicidade deles decorrente $(\mathrm{G} 1,2010)$.

A busca individual pela felicidade pressupõe a observância da felicidade coletiva, existente quando são adequadamente observados os itens que tornam mais feliz a sociedade, ou seja, justamente os direitos sociais $(\mathrm{G} 1,2010)$. É 
certo que a concretização dos direitos sociais não traz a garantia da felicidade subjetiva para cada cidadão individualmente, todavia, a felicidade coletiva proporciona a possibilidade de concretização do direito à busca pela felicidade, ou seja, a garantia de que cada indivíduo possa dedicar-se à concretização de sua felicidade individual, deixando de se preocupar com a satisfação de suas necessidades básicas ao longo de toda sua existência.

A partir do entendimento do que é a felicidade subjetiva e coletiva, e tendo em vista a necessidade de implementá-la, o impasse que se desenha não é a previsão legal ou fundamentação de tal direito e sim a sua concretização, haja vista a realidade da efetivação dos direitos humanos e sociais, dentre eles o direito ao trabalho, como será abordado a seguir.

\section{O DIREITO AO TRABALHO COMO MEIO DE CONCRETIZAÇÃO DO DIREITO À BUSCA PELA FELICIDADE}

Mesmo não havendo previsão explícita sobre $\mathrm{o}$ direito à busca pela felicidade no ordenamento jurídico pátrio, tal direito tem sido estampado em diversas decisões judiciais como desdobramento do princípio da dignidade da pessoa humana, conforme a seguir se demonstra:

HOMOFOBIA. DISCRIMINAÇÃO. RESCISÃO INDIRETA E INDENIZAÇÃO POR DANO MORAL. Para efeito de cumprimento das cláusulas ou produtividade no contrato de trabalho é absolutamente irrelevante a orientação sexual adotada pelo empregado, vez que se trata de questão estritamente relacionada à sua intimidade. In casu, a chefia adotou como forma de ofensa e constrangimento reiterado, os epítetos de "gay", "veado", "bicha" e "vadia", além de outras expressões chulas de cunho homofóbico e depreciativo, constituindo inequívoco atentado à dignidade do trabalhador, com alto grau de ofensividade e execração moral, mormente porque proferidas diante dos colegas. Com isto, o reclamante viu-se na contingência de ter que afastarse, pleiteando a rescisão indireta por culpa patronal (CLT, art. 483, b e e). O Judiciário tem se posicionado de forma vanguardista contra o conservadorismo e a ortodoxia, ao assegurar igualdade substantiva ao segmento perseguido e hostilizado que assume orientação sexual diversa do "padrão modelar", garantindo o direito à convivência, à formação da família e à união civil homoafetiva, cumprindo a promessa constitucional de igualdade e de organização da sociedade com vistas à felicidade. Recurso patronal ao qual se nega provimento. (TRT $2^{\mathrm{a}}$ Região. RO 00025070920115020311

SP 00025070920115020311 A28. Relator: Ricardo Artur Costa e Trigueiros. $4^{\mathrm{a}}$ Turma. Julgamento: 01/10/2013. Publicação: 11/10/2013) - grifo dos autores.

No caso acima exposto, verifica-se não apenas a relação do trabalho e do meio ambiente do trabalho equilibrado com a felicidade do trabalhador, que ao ser ofendido em seu locus laboral possui seu estado de ânimo abalado, mas, também, a questão do respeito à liberdade sexual como fator indispensável ao livre desenvolver-se como um indivíduo feliz.

Nesse sentido, conforme elucida Maria Berenice Dias, "às claras que o enlaçamento de vidas decorre da busca pela felicidade. Ainda que não esteja consagrado constitucionalmente, ninguém duvida que é um direito fundamental" (DIAS, s.d., online).

Outras condutas no âmbito laboral também geram discussão sobre a realização do trabalhador e sua felicidade, como é o caso da revista, discutida no julgado abaixo:

REVISTA PASSADA EM REVISTA -
SUPERAÇÃO DO IUS UTENDI ET ABUTENDI -
INVASÃO E PREDOMÍNIO DE PRINCÍPIOS
CONSTITUCIONAIS NO ORDENAMENTO
JURÍDICO-TRABALHISTA - COLISÃO E
SOLUÇÃO - IMPORTÂNCIA DA EFICÁCIA
HORIZONTAL DOS DIREITOS
FUNDAMENTAIS - A empresa tem o direito de
preservar o seu patrimônio, donde ser legítima a
revista, que também possui duas finalidades: a)
controle patrimonial; b) punição do ato de
desonestidade, que, por sua vez, pode se desdobrar
em: b1) advertência ou suspensão, visando à
recuperação do infrator; b2) dispensa, visando ao
afastamento de empregado cuja prática é nociva ao
bom ambiente de trabalho. Assim, a revista, em si,
não é boa nem ruim, desde que, por se tratar de um

REVISTA PASSADA EM REVISTA SUPERAÇÃO DO IUS UTENDI ET ABUTENDI INVASÃO E PREDOMÍNIO DE PRINCÍPIOS CONSTITUCIONAIS NO ORDENAMENTO JURÍDICO-TRABALHISTA - COLISÃO E SOLUÇÃO - IMPORTÂNCIA DA EFICÁCIA HORIZONTAL DOS DIREITOS FUNDAMENTAIS - A empresa tem o direito de preservar o seu patrimônio, donde ser legítima a revista, que também possui duas finalidades: a) controle patrimonial; b) punição do ato de desonestidade, que, por sua vez, pode se desdobrar em: b1) advertência ou suspensão, visando à recuperação do infrator; b2) dispensa, visando ao afastamento de empregado cuja prática é nociva ao não é boa nem ruim, desde que, por se tratar de um 
desdobramento do direito de propriedade, se faça revestida de sua função social. Constitui-se em instrumento à disposição da empregadora, que, no entanto, tem que utilizá-lo em consonância com os demais princípios constitucionais, dentre os quais se destaca o da dignidade da pessoa humana, que molda e conforma todo o ordenamento jurídico. Tratar o trabalhador com igualdade e com respeito à ética e à sacralidade do próximo, também é uma maneira de realizar justiça no ambiente de trabalho, que se constitui em um prolongamento do lar, da sociedade e da boa convivência, necessárias para a plena realização e para a felicidade do homem. Em suma, a revista praticada nos moldes acima apontados, concretiza, sob a ótica privada, a eficácia horizontal de importante direito fundamental, garantindo-se à empregadora, sem risco de transgressão a fruição de um direito constitucional. (TRT 3 ${ }^{\text {a }}$ Região. RO 282680800576 2008-102-03-00-7. Relator: Luiz Otavio Linhares Renault. $4^{\mathrm{a}}$ Turma. Publicação: DEJT 16/03/2009 13/03/2009, p. 44) - grifo dos autores.

Confere-se no julgado colacionado que o aspecto organizacional do trabalho, que engloba o poder do empregador de estipular revistas, possui papel importante no equilíbrio do meio ambiente do trabalho, podendo, se mal utilizado, causar severos danos ao trabalhador, não apenas em seu bem-estar no trabalho, mas, também, em outros aspectos da sua vida, como ao seu convívio familiar e social. Ao frustrar a boa convivência no âmbito laboral, ignorando a igualdade, o respeito e a ética no ambiente do trabalho, o empregador impede que o empregado possa galgar sua felicidade.

Além dos exemplos explicitados, há tantos outros casos de desrespeito às normas trabalhistas e à dignidade humana na seara juslaboral que acabam por frustrar a realização pessoal do indivíduo e seu direito à busca pela felicidade. Um trabalhador que exerce sua função em um ambiente de trabalho insalubre ou que convive com riscos diários de acidente do trabalho em função da inobservância de medidas de saúde e segurança no trabalho não possui condições psicológicas de dedicar-se à busca pela felicidade. Nas mesmas condições estaria um trabalhador que se ativa em jornadas extenuantes ou tem suprimido seu direito a férias, ou que é vítima de assédio moral ou dano existencial. Ainda, como se falar em direito à busca pela felicidade para um indivíduo que trabalha em condições análogas a de escravo?

Não há como se falar em busca pela felicidade, de forma subjetiva, garantida a cada indivíduo como forma de se autodeterminar e de escolher o que o faz feliz, caso não se garanta alguns direitos sociais mínimos (felicidade coletiva), como é o caso do direito ao trabalho digno, emancipador e realizador. Para isso, há que se buscar a efetivação dos direitos trabalhistas, de modo a impedir que o trabalho se torne degradante e prejudicial, sobretudo para a camada mais vulnerável da população.

Nesse sentido, de acordo com Alexandre Mendes (2011), a função do jurista, nesse cenário, não é a definição de uma gama de direitos nunca realizados, mas o conhecimento e o engajamento nas lutas que produzem homens portadores de direito. Deve-se preocupar com a concretização de direitos, de forma que se garanta a proteção humana em sua plenitude.

O Brasil, nas últimas décadas, manteve considerável desigualdade na distribuição de renda e elevados níveis de pobreza. É, sem dúvidas, um país desigual, exposto ao desafio histórico de enfrentar uma herança de injustiça social que exclui parte significativa de sua população do acesso a condições mínimas de dignidade e cidadania (BARROS, 2000). As condições de trabalho apenas refletem o quadro e ajudam a agravá-lo.

Segundo o IBGE, no terceiro trimestre de 2015, cerca de 92,1 milhões de brasileiros estavam empregados no Brasil (UOL, 2015), sendo que, segundo dados da Receita Federal do Brasil, o número de trabalhadores com renda superior a 160 salários mínimos no mesmo ano foi de 71.440; 20.738.173 tem uma renda inferior a 10 salários mínimos com maior concentração de população com renda entre 5 e 3 salários mínimos 
(ALVARENGA, 2015), sendo que tais números ignoram o trabalho informal, que acolhe grande parcela da mão de obra.

Além de um salário insuficiente, o trabalhador muitas vezes ainda integra um meio ambiente insalubre, degradante ou penoso. Segundo pesquisa elaborada em 2015, cerca de 734 julgados foram encontrados no âmbito dos Tribunais Regionais do Trabalho brasileiros, entre os anos de 2004 e 2014, pleiteando indenizações por dano existencial. Verificaram-se diversas situações de frustração de direitos trabalhistas que impediram de maneira severa a realização do projeto de vida do trabalhador ou o seu convívio social (SABONGI, 2015). Esse quadro demonstra a realidade degradante do trabalho brasileiro, que, ao invés de promover o bem-estar do trabalhador, o relega a condições laborais precárias, em detrimento do seu pleno desenvolvimento social.

Em suma, conforme assevera Victor Hugo de Almeida (2013, p. 198), "a melhoria das condições de vida, nela incluídas as condições de trabalho", capaz de conduzir o sujeito à felicidade, "não está necessariamente na esfera do consumo", razão pela qual "não há que se falar em consumo como um dos principais elementos do desenvolvimento social, sobrepondo-o ao trabalho"; "este sim, desde que em condições dignas e adequadas, importa em cidadania, dignidade, desenvolvimento, melhoria das condições de vida, justiça social e, inclusive, possibilita o acesso aos bens de consumo", efetivando o direito à felicidade.

No mesmo sentido, assevera Richard Easterlin (1995) que, ao longo de constatações empíricas, observou-se que o nível de felicidade analisado na população estadunidense não cresceu proporcionalmente ao crescimento econômico da população estudada, o que demonstra que a população com mais poder aquisitivo não é necessariamente a mais feliz.
Deve-se ainda ter em mente que, durante a vigência do contrato de trabalho, muitos trabalhadores não buscam a Justiça do Trabalho para pleitear direitos não adimplidos, em decorrência do receio de perder o emprego ou por receio de represália ao tentar buscar uma nova colocação profissional. Assim, constata-se a limitação do Poder Judiciário em promover a efetivação dos direitos trabalhistas e o trabalho digno e emancipador como condição à busca pela felicidade. Há que se pensar na concretização do direito a felicidade como dever do Estado não apenas no âmbito do Poder Judiciário, mas, também, por meio de políticas públicas que priorizem a conscientização da população e a efetivação das normas trabalhistas de forma a promover o bem-estar dos cidadãos trabalhadores.

Nesse cenário, torna-se retórico falar em direito à busca pela felicidade, uma vez que, para possibilitar a felicidade subjetiva, deve-se priorizar a coletiva, que depende da concretização dos direitos sociais, dentre eles o do trabalho. Em outras palavras, questiona-se se um indivíduo sem trabalho digno ou que dependa de um emprego em condições precárias para promover seu sustento e de sua família está em condições de buscar sua felicidade.

Observa-se que a felicidade coletiva, alcançada com a concretização dos direitos sociais, é pressuposto da garantia do direito à busca pela felicidade. Nesse sentido, analisar a realidade da concretização dos direitos humanos é essencial, uma vez que a mera discussão técnicoformal não tem o condão de concretizar o direito à busca pela felicidade.

\section{CONCLUSÃO}

É explícita a preocupação da Constituição Federal de 1988 com a pessoa humana e sua proteção ao salvaguardar a garantia do exercício dos direitos sociais e individuais, da liberdade, da 
segurança e do bem-estar. Em seu art. $1^{\circ}$, evidenciam-se, como fundamentos da República Federativa do Brasil e do Estado Democrático de Direito, a dignidade da pessoa humana (inciso III) e os valores sociais do trabalho (inciso IV). Ademais, o texto constitucional ainda eleva ao patamar de direitos fundamentais o direito ao trabalho (art. $5^{\circ}$, inciso XVIII, e artigos $6^{\circ}$ e $7^{\circ}$ ) e ao meio ambiente do trabalho equilibrado (art. 225 e 200, inciso VIII).

Assim, mesmo não havendo previsão explícita no ordenamento pátrio do direito à felicidade, tal direito tem sido estampado em diversas decisões judiciais como desdobramento do princípio da dignidade da pessoa humana, relacionando-se ainda com a concretização dos direitos sociais e dos valores sociais do trabalho, fundamentos previstos constitucionalmente.

Como foi demonstrado ao longo do presente estudo, o direito à felicidade se desdobra em duas esferas: a felicidade subjetiva (a busca pela felicidade individual) e a felicidade coletiva (a concretização da felicidade geral por meio da efetivação de direitos sociais). Não há como se falar na realização da primeira sem que se busque a promoção da segunda.

A concretização dos direitos sociais não conduz à garantia da felicidade subjetiva para cada cidadão individualmente, entretanto, a felicidade coletiva viabiliza a efetivação do direito à busca pela felicidade, ou seja, a garantia de que cada indivíduo possa dedicar-se à execução de sua felicidade individual, deixando de se preocupar com a satisfação de suas necessidades básicas ao longo de toda a sua existência.

Assim, para se garantir a busca pela felicidade, de forma subjetiva, garantida a cada indivíduo como forma de se autodeterminar e de escolher o que o faz feliz, deve-se assegurar a concretização de alguns direitos sociais mínimos (felicidade coletiva), como é o caso do direito ao trabalho digno, emancipador e realizador. Para isso, há que se buscar a efetivação dos direitos trabalhistas, de modo a impedir que o trabalho se torne degradante e prejudicial, sobretudo para a camada mais vulnerável da população.

Todavia, há um entrave entre o discurso e a prática dos direitos humanos, dentre eles os sociais, e o direito ao trabalho apenas reflete tal impasse. A universalidade dos direitos humanos defende inclusões em abstrato, as quais não se materializam em face de exclusões concretas, individuais e coletivas.

Analisar a realidade da efetivação dos direitos humanos é essencial, uma vez que a mera discussão técnico-formal não tem o condão de concretizar o direito à busca pela felicidade. É necessário que se implementem políticas públicas de conscientização que prezem pela efetivação dos direitos humanos, sociais e trabalhistas, de forma a promover o direito ao trabalho digno, realizador e emancipador, que corrobore com o bem-estar do trabalhador, possibilitando, assim, a felicidade em sua plenitude, tanto coletiva como subjetiva.

\section{REFERÊNCIAS}

ALMEIDA, Victor Hugo de. Consumo e trabalho: impactos no meio ambiente do trabalho e na saúde do trabalhador. 2013. Tese (Doutorado em Direito) - Faculdade de Direito da Universidade de São Paulo, USP, São Paulo, 2013.

; SOUZA, André Evangelista. O direito à saúde na perspectiva labor-ambiental. In: MIESSA, Élisson; CORREIA, Henrique. Temas atuais de Direito e Processo do Trabalho. Salvador: JusPODIVM, 2013. 
ALVARENGA, Darlan. 71 mil brasileiros concentram $22 \%$ de toda riqueza; veja dados da Receita. G1, São Paulo, 1 ago. 2015. Disponível em: <http://g1.globo.com/economia/noticia/2015/08/71-milbrasileiros-concentram-22-de-toda-riqueza-veja-dados-da-receita.html>. Acesso em: 29 jun. 2016.

BARROS, Ricardo Paes de; HENRIQUES, Ricardo; MENDONÇA, Rosane. Desigualdade e Pobreza no Brasil: retrato de uma estabilidade inaceitável. Rev. bras. Ci. Soc., São Paulo, v. 15, n. 42, p. 123142, fev. 2000.

BRASIL. Atividade legislativa. Senado Federal, Brasília, DF, 18 mar. 2015. Disponível em: <http://www25.senado.leg.br/web/atividade/materias/-/materia/97622>. Acesso em: 29 jun. 2016.

DIAS, Maria Berenice. Direito a felicidade. Disponível em: <http://www.mariaberenice.com.br/uploads/o_direito_\%E0_felicidade.pdf>. Acesso em: 23 jul. 2016.

EASTERLIN, Richard A. Will Raising the Incomes of All Increase the Happiness of All? Journal of Economic Behavior and Organization, n. 27, p. 35-48, 1995.

FREUD, Sigmund. El malestar en la cultura. Madrid: Alianza Editorial, 2002.

G1. Brasil é o $12^{\circ}$ país mais feliz do mundo, segundo pesquisa. G1, São Paulo, 19 jul. 2010. Disponível em: <http://blog.maisfeliz.org/?p=786>. Acesso em: 06 jul. 2016.

HOBBES, Thomas. Leviatã. São Paulo: Edipro, 2015.

HORBACH, Beatriz Bastide. Constitucionalizar a felicidade é cura ou placebo? Conjur, São Paulo, 3 ago. 2013. Disponível em: <http://www.conjur.com.br/2013-ago-03/observatorio-constitucionalconstitucionalizar-felicidade-cura-ou-placebo>. Acesso em: 01 jul. 2016.

KANT, Immanuel. Fundamentação da metafísica dos costumes. Tradução de Paulo Quintela. Lisboa: Ed. 70, 2004.

MACHADO, Costa. Constituição Federal interpretada. 5. ed. São Paulo: Manole, 2014.

MENDES, Alexandre. Joaquín Herrera Flores e a dignidade da luta. Revista Direito e Práxis, v. 2, n. 1, p. 77-96, 2011.

NUSSBAUM, Martha C. Who is the happy warrior? Philosophy poses questions to psychology. Journal of Legal Studies, v. 37, n. S2, p. S81-S113, jun. 2008.

OIT. Tendencias Mundiales del Empleo. $2014 . \quad$ Disponível: <http://www.ilo.org/global/research/global-reports/global-employment-trends/2014/lang-es/index.htm>. Acesso em: 06 jul. 2016.

ONUBR, ONU Brasil. A felicidade não é uma futilidade nem um luxo, diz secretário-geral da ONU em Dia Internacional. Disponível em: <https://nacoesunidas.org/a-felicidade-nao-e-uma-futilidadenem-um-luxo-diz-secretario-geral-da-onu-em-dia-internacional/>. Acesso em: 22 jun. 2016.

PAULI, Paulo César do Amaral de. La reparación del daño existencial en el derecho del trabajo brasileño como forma de protección a la dignidad de la persona humana. In: GARRIGA 
DOMÍNGUEZ, Ana; SÁNCHEZ BRAVO, Álvaro. Derechos humanos, protección medioambiental y nuevos retos sociales. Madrid: Editorial Dykinson, 2015.

RUBIN, Beatriz. O direito a busca pela felicidade. Revista Brasileira de Direito Constitucional, n. 16, p. 35-49, jul./dez. 2010.

RUBIO, David Sánchez. Derechos Humanos, no colonialidad y otras luchas por la dignidad: una mirada parcial y situada. Revista Campo jurídico, v. 3, n. 1, 2015.

SABONGI, Camila Martinelli. O dano existencial aplicado ao âmbito juslaboral. 2015.72 f. Trabalho de conclusão de curso (Graduação em Direito) - Faculdade de Ciências Humanas e Sociais da Universidade Estadual Paulista “Júlio de Mesquita Filho", UNESP, Franca, 2015.

SANTOS, Boaventura de S. Os direitos humanos na pós-modernidade. Direito e sociedade, Coimbra, n. 4, mar. 1989.

UOL. Desemprego sobe a 8,9\% no terceiro trimestre, o maior desde 2012, diz IBGE. UOL Economia, São Paulo, 24 nov. 2015. Disponível em: <http://economia.uol.com.br/empregos-ecarreiras/noticias/redacao/2015/11/24/desemprego-sobe-a-89-no-terceiro-trimestre-o-maior-desde2012-diz-ibge.htm>. Acesso em: 29 jun. 2016.

. ONU reconhece busca pela felicidade como objetivo fundamental. UOL Notícias, São Paulo, 19 jul. 2011. Disponível em: <http://noticias.uol.com.br/ultimas-noticias/efe/2011/07/19/onureconhece-busca-pela-felicidade-como-objetivo-fundamental.jhtm>. Acesso em: 22 jun. 2016.

VEENHOVEN, Ruut. Is happiness relative? Social Indicators Research, v. 24, p. 1-34, 1991.

WANDELLI, Leonardo Vieira. O direito ao trabalho como direito humano e fundamental. 2008. Monografia (Especialização em Direito) - Universidade Estadual do Paraná, Curitiba, 2008.

WOLKMER, Antônio Carlos. Pluralismo jurídico, direitos humanos e interculturalidade. Revista Sequência, n. 53, p. 113-128, dez. 2006.

Recebido em: 26/04/2017

Aceito em: 22/09/2017 
